Jurnal Sain Veteriner, Vol. 36. No. 1. Juni 2018, Hal. 24-31

DOI : $10.22146 /$ jsv.38475

ISSN 0126-0421 (Print), ISSN 2407-3733 (Online)

Tersedia online di https://jurnal.ugm.ac.id/jsv

\title{
Identifikasi Parasit pada Biawak Air (Varanus salvator)
}

\section{Identification of Parasites on Water Monitor Lizard (Varanus salvator)}

\author{
Muhammad Hanafiah ${ }^{1 *}$, Hoky Deora Alfiansyah ${ }^{2}$, Arman Sayuti $^{3}$ \\ ${ }^{1}$ Laboratorium Parasitologi, Fakultas Kedokteran Hewan, Universitas Syiah Kuala \\ ${ }^{2}$ Program Studi Pendidikan Dokter Hewan, Fakultas Kedokteran Hewan, Universitas Syiah Kuala \\ ${ }^{3}$ Laboratorium Klinik, Fakultas Kedokteran Hewan, Universitas Syiah Kuala \\ *E-mail: hanafi_2015@unsyiah.ac.id
}

Naskah diterima : 29 Mei 2017, direvisi : 6 September 2017, disetujui : 30 Mei 2018

\begin{abstract}
This research has purposes to identify parasites as well as to reward determining the prevalence of parasites on water monitor lizard (Varanus salvator) was captured in Banda Aceh. As many as 50 water monitor lizard were used this research and examined at the Laboratory of Parasitology, Faculty of Veterinary Medicine University of Syiah Kuala. Examination of ectoparasites on the surface of the body was done by direct examination. Endoparasit examination carried out by observation in blood using the blood smear and centrifugation techniques microhematocrit (mHCT), while fecal examination using flotation method, Borray sedimentation and digestive tract surgery digestive tract surgery if obtained at least 3 types of helminth eggs ( 1 cestodes, 1 nematodes, and 1 trematodes). Results of observation on blood is no parasites were found. Observations on the skin was obtained ectoparasites Amblyomma sp. with a prevalence rate of $100 \%$ category always. Observations of feces obtained Ascaris sp. with a prevalence rate of $74 \%$ category usualy and Strongyloides spp. with a prevalence rate of $8 \%$ category sometimes. Based on these results it can be concluded that the parasites that can infest the water monitor lizard (Varanus salvator) is Amblyomma sp, Ascaris sp, and Strongyloides spp. with variant prevalence rates.
\end{abstract}

Key words: Varanus salvator, parasite, Amblyomma sp, Ascaris sp, Strongyloides spp.

\begin{abstract}
Abstrak
Penelitian ini bertujuan mengidentifikasi jenis parasit serta menentukan tingkat prevalensi jenis-jenis parasit pada biawak air (Varanus salvator) yang ditangkap di Banda Aceh. Biawak yang digunakan sebanyak 50 ekor dan diperiksa di Laboratorium Parasitologi Fakultas Kedokteran Hewan Universitas Syiah Kuala. Pemeriksaan ektoparasit pada permukaan tubuh dilakukan dengan cara langsung. Pemeriksaan endoparasit dilakukan dengan cara pengamatan pada darah dengan menggunakan metode darah apus dan teknik sentrifugasi mikrohematokrit (mHCT), sedangkan pemeriksaan feses menggunakan metode apung, sedimentasi Borray dan pembedahan saluran pencernaan dilakukan apabila didapatkan minimal 3 jenis telur cacing (satu cestoda, satu nematoda, dan satu trematoda). Identifikasi parasit dilakukan secara mikroskopis. Hasil pengamatan pada darah tidak ditemukan parasit. Pengamatan pada kulit didapatkan ektoparasit Amblyomma sp. dengan tingkat prevalensi 100\% kategori selalu. Pengamatan pada feses ditemukan Ascaris sp. dengan tingkat prevalensi 74\% kategori biasa dan Strongyloides spp. dengan tingkat prevalensi 8\% kategori kadang-kadang. Berdasarkan hasil penelitian, dapat disimpulkan bahwa ada beberapa jenis parasit yang dapat menginfestasi biawak air (Varanus salvator) antara lain Amblyomma sp, Ascaris $s p$, dan Strongyloides spp. dengan tingkat prevalensi berbeda-beda.
\end{abstract}

Kata kunci: biawak air, parasit, Amblyomma sp, Ascaris sp, Strongyloides spp.

\section{Pendahuluan}

Indonesia merupakan negara yang memiliki potensi keanekaragaman satwa liar yang tinggi. Keanekaragaman tersebut dapat terlihat dari beraneka ragamnya spesies satwa liar yang terdiri atas burung, mamalia, reptil dan amphibi yang dapat ditemukan di wilayah Indonesia. Salah satu contoh kekayaan yang dimiliki oleh Indonesia adalah spesies varanid yaitu biawak air (Varanus salvator) (Gumilang, 2001)

Indonesia memiliki tujuh spesies varanid yaitu $V$. beccani, $V$. doreanus, $V$. dumerilii, $V$. jobiensis, $V$. rudicolis, V. salvadorii dan V. salvator (Rusmanto, 
2012). Convention on International Trade in Endangered Species/CITES (2013) menyatakan, biawak air termasuk ke dalam Appendix II, dimana satwa tersebut tidak terancam punah tetapi perdagangannya harus dikontrol untuk menghindari penggunaan berlebihan yang dapat mengancam populasinya. Berdasarkan Surat Keputusan Menteri Kehutanan dan Perkebunan Nomor: 461/Kpts-II/1999 tentang penetapan musim berburu jenis-jenis satwa buru di taman buru dan areal buru, biawak air termasuk ke dalam salah satu hewan yang diburu.

Dewasa ini keinginan masyarakat menjadikan reptil sebagai hewan ternak mulai banyak di Indonesia. Biawak merupakan satwa yang memiliki potensi komersial. Kulitnya yang indah, kuat dan dagingnya yang mempunyai khasiat sebagai obat penyakit kulit banyak diincar oleh pemburu-pemburu (Ramadhan, 2011). Kulit biawak merupakan bagian yang paling populer dan diminati dalam perdagangan, dikarenakan pola dan seratnya yang unik, awet, dan memiliki nilai ekonomi yang tinggi. Pada tahun 1990, sebanyak 2,5 juta kulit biawak yang berhasil dikumpulkan untuk diperdagangkan (Bennet, 1998). Biawak air memiliki distribusi dalam jumlah yang besar dan umum ditemukan di berbagai habitat, namun spesies ini dapat terancam punah akibat diburu untuk dimakan, dieksploitasi untuk perdagangan kulit, dan terancam oleh kerusakan habitat (Bennett and Sweet, 2010).

Berdasarkan habitat dan makanannya, biawak memiliki kemungkinan tinggi terinfestasi oleh parasit. Beberapa faktor yang dapat menunjang untuk hidup dan berkembangnya parasit antara lain makanan yang tidak sehat, lingkungan yang tercemar, dan perilaku hidup individu (Natadisastra dan Agoes, 2009). Infestasi parasit menimbulkan banyak kerugian baik untuk pengelola atau pemelihara maupun satwa yang terinfeksi dikarenakan dapat mengakibatkan penurunan kualitas dari biawak baik di penangkaran maupun di alam (Ramadhan, 2011). Jenis parasit yang menginfestasi biawak air berdasarkan beberapa penelitian yaitu, Amblyomma sp, Aponomma sp, Macrochelidae (Ramadhan, 2011), Haemogregarina sp (Ramdan dkk., 1996), Trypanosoma brucei (Njagu dkk., 1999), Artyfechinostomum (Premvati dan Vibha, 1974), Meristocotyle provitellaria (Liu, 2002), Indicovalipora indicus (Suryawanshi dkk., 2011), Panceriella emiratensis (Schuster, 2012), Ophiovalipora lingampetensis (Kalyankar dkk, 2010), Strongyloides spp., Oswaldofilaria chabaudi, Ascaris (Rataj dkk., 2011), Kalicephalus guangdongensis (Zhang dkk., 2011), dan Abbreviata perenticola (Jones, 1985).

Salah satu upaya untuk melestarikan biawak adalah dengan menyediakan data dasar termasuk dari aspek parasit. Data tersebut diperlukan sebagai informasi dan bahan pendukung dalam program konservasi bagi para peternak biawak air. Salah satu aspek yang perlu untuk diteliti yaitu identifikasi parasit yang menginfestasi biawak air secara morfologi. Berdasarkan laporan yang didapatkan, dapat diduga bahwa terdapat banyak parasit yang dapat menginfestasi biawak air (Varanus salvator).

\section{Materi dan Metode}

Penelitian ini menggunakan sampel biawak air 50 ekor yang ditangkap langsung dari alam di Banda Aceh. Sampel kemudian dibawa ke Laboratorium Parasitologi Fakultas Kedokteran Hewan Universitas Syiah Kuala untuk diperiksa. Pemeriksaan ektoparasit pada biawak dimulai dengan koleksi spesimen ektoparasit. Pengambilan ektoparasit dilakukan secara manual menggunakan pinset, dan diambil dari kepala hingga ekor. Spesimen ektoparasit yang telah didapat selanjutnya dilakukan pengawetan. Tata cara pengawetan tercantum dalam Hadi dkk. yang disitasi oleh Ramadhan (2011). Untuk pengawetan basah dilakukan dengan cara menyimpan spesimen ektoparasit dalam tabung yang berisi $\mathrm{KOH}$ 
$10 \%$. Setelah spesimen dikumpulkan, ektoparasit di letakkan di cawan petri dan diperiksa menggunakan mikroskop stereo.

Pemeriksaan endoparasit pada darah dimulai dengan pengambilan sampel dari vena coccygeal ventral (Stahl, 2006) dengan menggunakan spuit $3 \mathrm{ml}$ berisi EDTA, selanjutnya dilakukan pembuatan preparat darah apus dan tehnik sentrifugasi mikrohematokrit. Prosedur pembuatan preparat darah apus menurut Chalid (2013), sebanyak 1 tetes darah diteteskan di atas object glass. Kemudian object glass yang lain letakkan tepat di ujung tetesan darah, dengan membentuk sudut $45^{\circ}$ antara object glass I dan ke II kemudian dorong ke arah depan dengan cepat agar terbentuk lapisan darah yang tipis. Slide yang sudah dibuat ditunggu sampai darahnya mengering selanjutnya dilakukan pewarnaan. Object glass direndam dalam metil alkohol selama 10 menit. Seterusnya diwarnai dengan giemsa dan tunggu selama 10 menit, kemudian dicuci dengan akuades sampai bersih biarkan sampai mengering. Untuk melihat parasit diteteskan minyak emersial pada sediaan apus darah dan kemudian diperiksa menggunakan mikroskop.

Prosedur tehnik sentrifugasi mikrohematokrit (mHCT) menurut Woo yang disitasi oleh Solihat (2002), sampel darah yang ditampung dalam tabung yang mengandung antikoagulan EDTA dimasukkan ke dalam tabung mikrohematokrit kira-kira 3/4 bagian dari isi tabung kapiler tersebut. Salah satu ujung tabung mikrohematokrit ditutup dengan cristaseal. Buka penutup plate tempat tabung kapiler dan letakkan tabung berisi darah pada plate dengan bagian ujung kapiler yang disumbat berada di luar. kemudian plate ditutup kembali. Putar alat sentrifus mikrohematokrit selama 5 menit dengan kecepatan $12.000 \mathrm{rpm}$. Tabung kapiler ditempatkan pada objek glass khusus tabung kapiler yang ada celah di tengahnya. kemudian diperiksa di bawah mikroskop pada bagian buffy coat .
Pemeriksaan endoparasit pada feses dimulai dengan koleksi feses pada biawak air, kemudian dilakukan metode apung dan metode sedimentasi Borray. Prosedur metode apung menurut Brown yang disitasi oleh Nezar (2014), sampel feses ditimbang sebanyak 3 gram dan dimasukkan dalam mortar. Mortar diisi larutan garam jenuh (Brine) sebanyak $5 \mathrm{ml}$ dan dihomogenkan. Sampel dimasukkan ke tabung reaksi kemudian larutan garam jenuh ditambahkan lagi hingga cembung dan didiamkan selama 30 menit. Selanjutnya mulut tabung ditutup dengan cover glass. Cover glass diangkat dan diletakkan di atas object glass kemudian diamati menggunakan mikroskop. Prosedur metode sedimentasi Borray menurut Hambal dkk. (2013), sebanyak \pm 3 gram feses dimasukkan ke dalam mortar dan ditambahkan $60 \mathrm{ml}$ air seterusnya ditetesi sabun secukupnya dan digerus sampai homogen. Larutan disaring dengan saringan teh ke dalam gelas beaker. Material yang tinggal disaring kemudian disemprot dengan air kecepatan tinggi, dan didiamkan selama 15 menit. Supernatan dibuang dan metode ini diulang sekali lagi, kemudian sedimen yang tertinggal diteteskan dengan methylene blue $1 \%$ untuk membedakan material yang berasal dari tumbuhan dengan telur trematoda (Fasciola spp). Sedimentasi yang tersisa dimasukkan ke dalam cawan petri yang sudah diberi garis untuk orientasi. Selanjutnya dilihat di bawah mikroskop keberadaan telur Fasciola sp yang berwarna kuning keemasan. Telur yang diperoleh dihitung dan dicatat jumlahnya.

Pemeriksaan endoparasit pada feses apabila ditemukan 3 telur cacing (satu cestoda, satu nematoda, dan satu trematoda), pemeriksaan dilanjutkan dengan pembedahan untuk koleksi sampel cacing. Biawak air yang telah diperoleh dieutanasi dengan kloroform. Setelah biawak mengalami dieutanasia, segera dilakukan pembedahan. Pemeriksaan dengan cara pembedahan saluran pencernaan menurut Krone (2007), saluran pencernaan disayat dari oesofagus 
secara longitudinal sampai kloaka kemudian dibuka dan diperiksa. Kerokan dari lapisan mukosa usus harus diperiksa untuk melihat ookista. Cacing harus ditangani dengan hati-hati agar tidak menghancurkan yang terpenting untuk identifikasi. Cacing dikoleksi ke dalam tabung spesimen yang berisi BNF 10\% (Buffered-Neutral Formalin). Cacing yang telah dikoleksi diidentifikasi menggunakan mikroskop.

\section{Hasil dan Pembahasan}

Berdasarkan hasil penelitian yang telah dilakukan pada 50 ekor biawak air yang di tangkap di Banda Aceh diperoleh hasil antara lain pengamatan pada darah tidak didapatkan parasit. Pengamatan pada kulit ditemukan satu jenis ektoparasit yaitu Amblyomma sp. sedangkan pengamatan pada feses didapatkan Ascaris sp., dan Strongyloides spp. seperti terlihat pada Tabel 1 di bawah ini.

Tabel 1. Predileksi dan prevalensi Amblyomma sp. Ascaris sp. dan Strongyloides spp. pada biawak air (Varanus salvator) yang diperiksa ( $\mathrm{n}=50$ ekor biawak)

\begin{tabular}{ccccc}
\hline Parasit & Predileksi & $\begin{array}{c}\text { Jumlah biawak air ter infeksi// } \\
\text { total sampel }\end{array}$ & & Prevalensi (\%) \\
\hline Amblyomma sp. & Kulit & $50 / 50$ & 100 \\
\cline { 2 - 4 } \cline { 2 - 4 } Ascaris sp. & Organ lain & $\begin{array}{c}\text { Saluran } \\
\text { pencernaan }\end{array}$ & $37 / 50$ & 0 \\
\hline Strongyloides spp. & $\begin{array}{c}\text { Organ } \\
\text { pencernaan }\end{array}$ & $4 / 50$ & 74 \\
\hline
\end{tabular}

Dari Tabel 1. di atas terlihat bahwa tingkat prevalensi ektoparasit Amblyomma sp. pada biawak air yaitu 100\%. Berdasarkan Williams dan Williams (1996), infestasi Amblyomma sp. termasuk dalam kategori selalu. Tingginya tingkat prevalensi Amblyomma sp. pada biawak kemungkinan karena biawak merupakan hospes spesifik yang menyerang reptil termasuk biawak (Ramadhan, 2011). Infestasi juga didukung dengan habitat Amblyomma sp pada daerah rerumputan dan terkadang pada daerah hutan (Weberm and Small, 2012).

Amblyomma sp. ditemukan banyak di pangkal leher dan pangkal kaki pada biawak air seperti yang terlihat pada Gambar 1. Infestasi Amblyomma sp. pada biawak air juga dilaporkan oleh Ramadhan (2011)

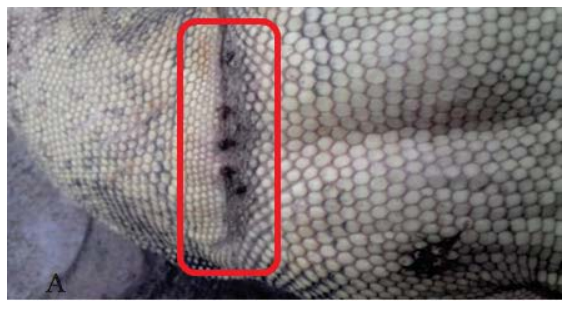

dimana ektoparasit ini ditemukan pada daerah kaki depan, kaki belakang, punggung, perut, dan ekor, namun tidak melaporan tingkat prevalensi. Amblyomma sp. memiliki tiga stadium dan hewan yang sama dapat menjadi induk semang yang sama. Amblyomma $s p$. pada stadium larva, stadium nimfa, dan stadium dewasa akan menempel pada tubuh induk semang kemudian jatuh untuk bertelur (Levine, 1990). Akibat dari infestasi ektoparasit antara lain kekurangan darah (anemia), kerusakan kulit atau iritasi, alergi sehingga menyakiti diri sendiri atau self wounding dengan mencakar atau pun menggigit bagian tubuh yang terasa gatal akibat ektoparasit (Wall and Shearer 2001).

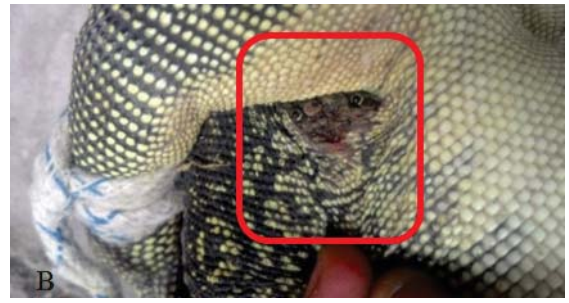

Gambar 1. Letak Amblyomma sp yang ditemukan pada biawak. A. Pangkal leher, B. Pangkal kaki (menggunakan foto kamera). 
Morfologi genus Amblyomma sp. biasanya ornata (memiliki hiasan skutum), memiliki mata, memiliki palpus panjang, seperti yg terlihat pada Gambar 2. (Levine, 1990). Kolonin (2009) mengatakan bahwa genus Amblyomma sp. yang terdapat pada famili Varanidae di Indonesia antara lain

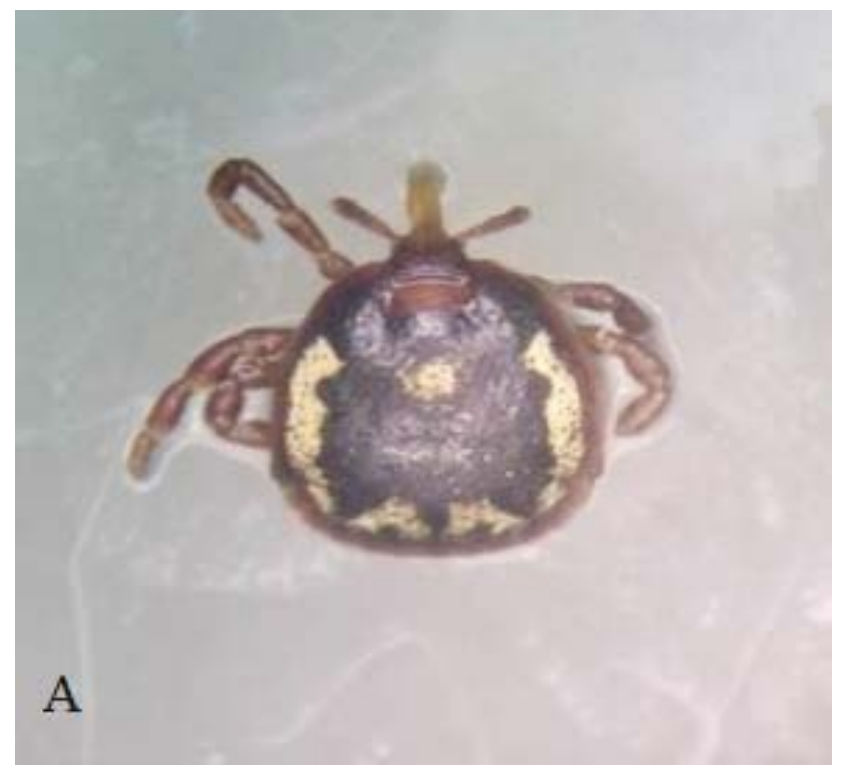

Gambar 2. Amblyomma sp., A. bagian dorsal, B. bagian ventral (pebesaran 10 x 40 )

Dari Tabel 1 juga dapat dilihat bahwa tingkat prevalensi endoparasit Ascaris sp. pada biawak air cukup tinggi yaitu 74\%. Berdasarkan Williams dan Williams (1996), infestasi Ascaris sp. termasuk dalam kategori biasa. Infestasi Ascaris $s p$. juga dilaporkan oleh Rataj dkk. (2011), namun tidak melaporkan tingkat prevalensi. CDC (2016) mengatakan, individu dapat terinfestasi Ascaris sp. dikarenakan mengkonsumsi makanan yang telah terkontaminasi dari telur Ascaris $s p$ yang berada di tanah. Infestasi Ascaris sp juga didukung oleh kebiasaan biawak selain memakan jenis pakan yang segar juga sangat menyukai pakan dalam bentuk bangkai atau daging yang membusuk (McCoy yang disitasi oleh Iyai dan Pattiselanno, 2006).

Telur Ascaris sp. yang berasal dari feses individu terinfeksi akan tersimpan di tanah. Ascaris $s p$. dewasa hidup di lumen usus kecil. Cacing betina dapat

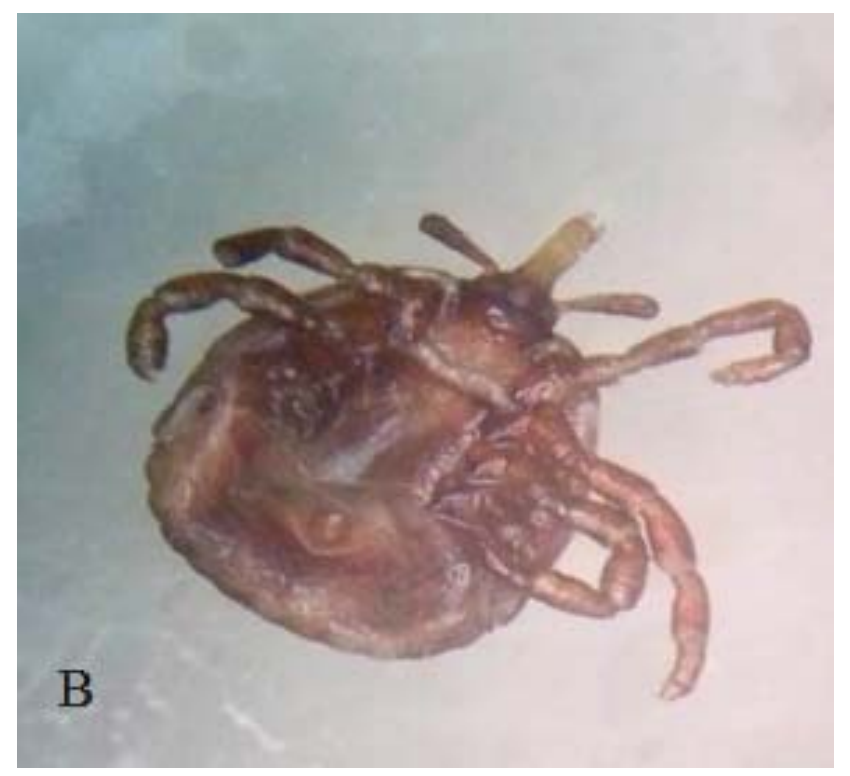

Amblyomma robinsori dan Amblyomma helvolum. Amblyomma robinsori wilayah penyebarannya di Pulau Komodo. Amblyomma helvolum wilayah penyebarannya di Sumatera, Jawa, Kalimantan, Sulawesi, Pulau Komodo, Flores, dan Tanimbar.

menghasilkan sekitar 200.000 telur per hari. Telur fertil menjadi infektif setelah 18 hari sampai beberapa minggu, tergantung pada kondisi lingkungan (optimum: lembab dan hangat). Setelah telur infektif yang tertelan, larva menetas dan berkembang di usus (CDC, 2016). Cuomo dkk. (2009), mengatakan, morfologi telur ascaris memiliki ukuran kisaran $60 \mu \mathrm{m}$ x $45 \mu \mathrm{m}$, berbentuk bulat atau lonjong, berwarna coklat atau kuning kecoklatan, cangkang telur tebal dan berisi 2,4 , atau lebih sel atau sepenuhnya berisi larva seperti yang terlihat pada Gambar 3 


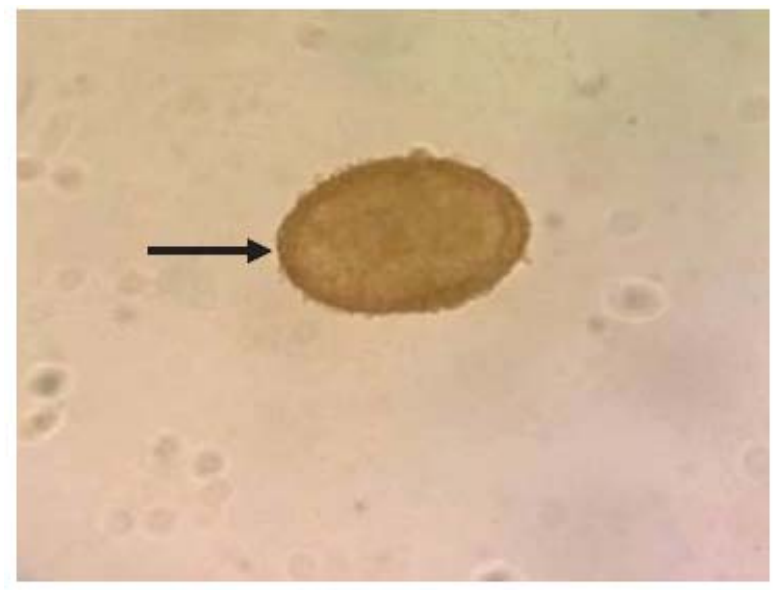

Gambar 3. Telur Ascaris sp (pebesaran $400 \mathrm{X}$ )

Selain Amblyommasp.dan Ascaris sp. Tabel $1 \mathrm{di}$ atas juga dapat dilihat bahwa tingkat prevalensi endoparasit Strongyloides spp. pada biawak air yaitu 8 \%. Berdasarkan Williams dan Williams (1996), infestasi Strongyloides spp. termasuk dalam kategori kadang-kadang. Infestasi Strongyloides spp. pada biawak air dapat dikarenakan Strongyloides spp. dapat menginfestasi melalui dua jalur yaitu melui kulit dan pencernaan (Levine, 1990). Infestasi Strongyloides Spp. juga dilaporkan oleh Rataj dkk. (2011), namun tidak melaporkan tingkar prevalensi.

Cacing betina menghasilkan telur berembrio atau larva yang keluar bersama feses. Larva stadium pertama rabtidiform dan memakan mikroorganisme yang berada dalam feses hingga menjadi larva stadium ketiga. Larva menjadi larva stadium ketiga dalam 2 tipe. Beberapa larva stadium ketiga memiliki esofagus filariform (silindris) dan menginfeksi vertebrata dengan menembus kulit atau tertelan. Setelah memasuki kulit, larva stadium ketiga menuju kapiler dan terbawa darah menuju paru-paru, masuk ke saluran pernapasan, bermigrasi ke trakea, dan bermigrasi ke esofagus menuju usus halus. Larva menjadi larva stadium keempat dan dewasa saat berada di usus halus. Apabila tertelan, larva stadium ketiga lansung menuju usus halus dan berkembang (Levine, 1990).

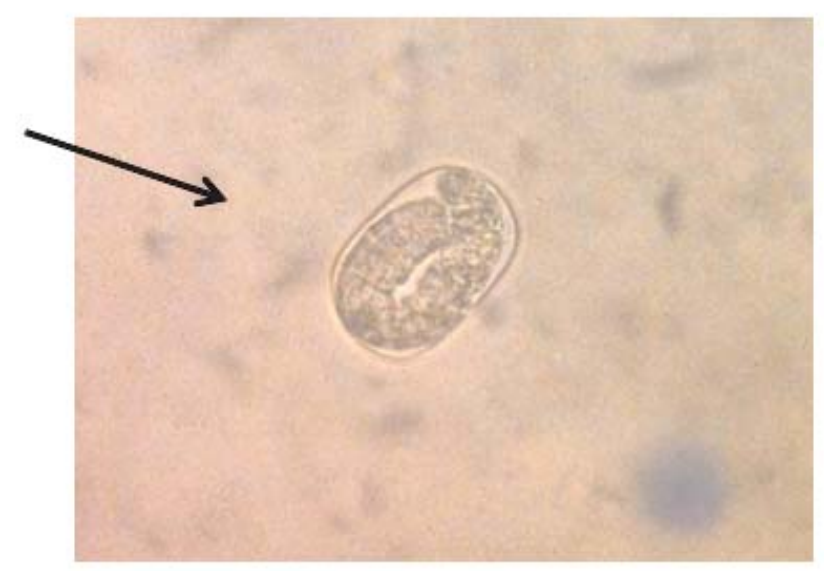

Gambar 4. Telur Strongyloides spp. (pebesaran 400 X)

Viney and Look (2007) mengatakan, telur Strongyloides spp. memiliki panjang 40-85 $\mu \mathrm{m}$, dengan dinding tipis dan mengandung larva yang dapat dilihat pada Gambar 4. Strongyloides spp. merupakan jenis parasit yang dapat menginfestasi mamalia, unggas, reptil, dan amfibi. 


\section{Kesimpulan}

Berdasarkan hasil penelitian dapat disimpulkan bahwa parasit yang dapat menginfestasi biawak air (Varanus salvator) yaitu Amblyomma sp. dengan tingkat prevalensi 100\%, Ascaris sp. dengan tingkat prevalensi 74\%, dan Strongyloides spp. dengan tingkat prevalensi $8 \%$.

\section{Saran}

Diperlukan penelitian lebih lanjut untuk mengidentifikasi parasit pada biawak air (Varanus salvator) di organ lainnya.

\section{Ucapan Terima Kasih}

Peneliti mengucapka terima kasih kepada Kepala Laboratorium Parasitologi, Dekan Fakultas Kedokteran Hewan Universitas Syiah Kuala yang telah memberikan izin untuk melakukan penelitian dan juga Drh. Winaruddin, M. Si yang telah membantu dalam identifikasi ektoparasit pada biawak air

\section{Daftar Pustaka}

Bennett, D. 1998. Monitor Lizard: Natural History. 2nd ed. Biology Husbandary, Frankfurt.

Bennett, D. and S.S. Sweet. 2010. Varanus Indicus. The IUCN Red List of Threatened Species 2010 : e. T 178416 A 7542350 . http://www.iucnredlist. org/details/178416/0. 20 Januari 2016.

CDC. 2016. Parasites-Ascariasis. 18 Desember 2015.

Chalid, M. 2013. Morfologi Eritrosit Pada Sediaan Apus Darah Tepi (SADT) Sampel Dengan Hasil Pemeriksaan One Tube Osmotic Fragility Test (Otoft) Positif. Skripsi. Fakultas Kedokteran. Universitas Kristen Maranatha. Bandung.

[CITES] Convention of International Trade in Endageres Species of Wild Fauna and Flora. 2013 . A p pend i ce s I, I I, I I . $\mathrm{http} / / w w w$. cites.org/eng/app/ appendices.php. 04 Desember 2015.

Cuomo, M.J., L.B. Noel, and D.B. White. 2009. Diagnosing medical parasites: a public health officers guide to assisting laboratory and medical officers. Air Education and Training Command Randolph. USA. 77-79.

Foryt, W.J. 2001. Vererinary Parasitology Reference Manual. IOWA State University. USA.

Gumilang, R. 2001. Populasi dan Penyebaran Biawak Air Asia (Varanus salvator) di Suaka Margasatwa Pulau Rambut, Jakarta. Skripsi. Fakultas Kehutanan. Institut Pertanian Bogor, Bogor.

Hambal, M., A. Sayuti, dan A. Dermawan. 2013. Tingkat Kerentanan Fasciola gigantica pada Sapi dan Kerbau di Kecamatan Lhoong Kabupaten Aceh Besar. Jurnal Medika Veterinaria, 7(1): 49-53.

Iyai, D.A., dan F. Pattiselanno. 2006. Diversitas dan Ekologi Biawak (Varanus indicus) di Pulau Pepaya Taman Nasional Teluk Cenderawasih, Irian Jaya Barat. Biodiversitas. 7(2): 181-186.

Jones, H.I. 1985. Gastrointestinal nematodes of the perentie, Varanus giganteus (Grey). Western Australia, with description of a new species of Abbreviata Travassos (Nematoda: Physalopteridae). Records of the Western Australian Museum, 12(3): 379-387.

Kalyankar, K.V., S.S. Nanware, and D.B. Bhure. 2010. Biosystematic studies on dilepididean cestode genus Ophiovalipora HSU, 1935 with a report of a new species from Varanus salvator. Asian Journal of Animal Science, 5(1): 78-80.

Kementrian Lingkungan Hidup dan Kehutanan. 1999. Lampiran Keputusan Menteri Kehutanan dan Perkenunan Nomor: 461/Kpts-II/1999. .

Kolonin GV. 2009. Fauna of Ixodid ticks of the world. www.kolonin.org. 16 Januari 2017.

Krone, O. 2007. Endoparasites. Raptor Research and Management Techniques. Zoo and Wildlife Research (IZW). Jerman : 318-328.

Levine, N.D. 1990. Buku pelajaran parasitologi veteriner. Gajah Mada University Press. Yogyakarta.

Liu, W., Q.K. Li, H.H. Shih, and Z.Z. Qiu. 2002. Meristocotyle provitellaria sp. nov.(Digenea: Meristocotylidae) from Varanus salvator in China. Zoological Studies-Taipei. 41(3): 283287. 
Natadisastra, D. dan R. Agoes. 2009. Parasitologi kedokteran: ditinjau dari organ tubuh yang diserang. EGC. Jakarta.

Nezar, M.R. 2014. Jenis Cacing pada Feses Sapi di TPA Jati Barang dan KTT Sidomulyo Desa Nongkosawit Semarang. Skripsi. Fakultas Matematika dan Ilmu Pengetahuan Alam. Universitas Negeri Malang.

Njagu, Z., S. Mihok, E. Kokwaro, and D. Verloo. 1999. Isolation of Trypanosoma brucei from the monitor lizard (Varanus niloticus) in an endemic focus of Rhodesian sleeping sickness in Kenya. Acta tropica. 72(2): 137-148.

Premvati, G., and P. Vibha. 1974. On Artifechinostomum malayanum (Leiper, 1911) Mendheim, 1943 (Trematoda: Echinostomatidae) with synonymy of allied species and genera. Proceedings of the Helminthological Society of Washington. 41(2): 151-160.

Ramadhan, R.A. 2011. Ragam Jenis Ektoparasit dan Manajemen Penangkaran Biawak. Skripsi. Fakultas Kehutanan. Institut Pertanian Bogor. Bogor.

Ramdan, N.F., M.F.A. Saoud, S.H. Mohammed, and S.M. Fawzi. 1996. On a new haemogregarine of Varanus griseus from Egypt. Faculty of Science, University of Qatar, State of Qatar. 16(1): 119125.

Rataj, A.V., R. Lindtner-Knific, K. Vlahović, U. Mavri, and A. Dovč. 2011. Parasites in pet reptiles. Acta Veterinaria Scandinavica. 53(1): 5-7.

Rusmanto. 2012. Biawak Air Tawar (Varanus salvator), Varanid Paling Komersial di Indonesia . Buletin Chelonia. Kalimantan Timur.

Schuster, R. 2012. Panceriella miratensis (Eucestoda, Linstowiidae) from desert monitor lizard, Varanus griseus (Daudin, 1803) in the United
Arab Emirates. Acta Parasitologica. 57(2): 167170.

Solihat, L. 2002. Proses Pemeriksaan Sampel Penyakit-Penyakit Parasit Darah di Laboratorium Parasitologi BALITVET. Balai Penelitian Veteriner. Bogor.

Stahl, S.J. 2006. Reptile hematology and serum chemistry. Proceedings of the North American Veterinary Conference (Orlando, Florida. 1673.

Suryawanshi, S.G., D.K. Mhaske, H.K. Bhagwan, and G.B. Shinde. 2011. On a new cestode, Indicovalipora indicus sp. nov.(Cestoda: Dilepididae) from Varanus indicus at Hiradgaon (MS) India. Asian Journal of Animal Science. 6(1):30-31.

Viney, M.E., and J.B. Lok. 2007. Strongyloides spp. WormBook: the online review of $\mathrm{C}$. elegans Biology, 1-15. .

Wall, R. and D. Shearer. 2001. Veterinary Ectoparasites : Biology, Pathogy and Control. Blackwell Science Ltd.

Weber, M. and C. Small 2012. "Amblyomma cajennense" (On-line), Animal Diversity http://animaldiversity.org/accounts/Amblyom ma_cajennense/29 Januari 2017.

Williams, E.H.J. and L.B. Williams. 1996. Parasites of Offshore Big Game Fishes of Puerto Rico and The Western Atlantic. Departement of Natural and Environmental Resources dan University of Puerto Rico. Puerto Rico. $383 \mathrm{hlm}$.

Zhang, H., S. Zhang, and L. Zhang. 2011. Two species of the genus Kalicephalus Molin, 1861 (Nematoda, Diaphanocephaloidea) from the water monitor, Varanus salvator (Laurenti, 1768) in Guangdong Province, China. Acta Parasitologica. 56(1): 48-53. 